NBER WORKING PAPER SERIES

\title{
SUFFICIENT STATISTICS REVISITED
}

\author{
Henrik Kleven \\ Working Paper 27242 \\ http://www.nber.org/papers/w27242 \\ NATIONAL BUREAU OF ECONOMIC RESEARCH \\ 1050 Massachusetts Avenue \\ Cambridge, MA 02138 \\ May 2020
}

I thank Felix Bierbrauer, Claus Kreiner, Magne Mogstad, Emmanuel Saez, Stefanie Stantcheva, and Owen Zidar for comments and discussions. The views expressed herein are those of the author and do not necessarily reflect the views of the National Bureau of Economic Research.

NBER working papers are circulated for discussion and comment purposes. They have not been peer-reviewed or been subject to the review by the NBER Board of Directors that accompanies official NBER publications.

(C) 2020 by Henrik Kleven. All rights reserved. Short sections of text, not to exceed two paragraphs, may be quoted without explicit permission provided that full credit, including () notice, is given to the source. 
Sufficient Statistics Revisited

Henrik Kleven

NBER Working Paper No. 27242

May 2020

JEL No. D01,D04,D1,D6,H0,H2,H3,J08,J2,J38

\begin{abstract}
$\underline{\text { ABSTRACT }}$
This paper reviews and generalizes the sufficient statistics approach to policy evaluation. The idea of the approach is that the welfare effect of policy changes can be expressed in terms estimable reduced-form elasticities, allowing for policy evaluation without estimating the structural primitives of fully specified models. The approach relies on three assumptions: that policy changes are small, that government policy is the only source of market imperfection, and that a set of high-level restrictions on the environment and on preferences can be used to reduce the number of elasticities to be estimated. We generalize the approach in all three dimensions. It is possible to develop transparent sufficient statistics formulas under very general conditions, but the estimation requirements increase greatly. Starting from such general formulas elucidates that feasible empirical implementations are in fact structural approaches.
\end{abstract}

\author{
Henrik Kleven \\ Department of Economics \\ Princeton University \\ 238 Julis Romo Rabinowitz Building \\ Princeton, NJ 08544 \\ and CEPR \\ and also NBER \\ kleven@princeton.edu
}




\section{Introduction}

The last decade of research on policy evaluation and welfare analysis has seen an explosion in the use of a term: sufficient statistics. The idea of the sufficient statistics approach is that the welfare effects of policy changes can be expressed in terms of estimable elasticities, allowing for policy evaluation without making parametric assumptions or estimating the structural primitives of fully specified models. Chetty (2009b) coined the phrase, arguing that the approach combines the best of reduced-form and structural approaches: credible identification of causal effects and the ability to make welfare predictions.

To illustrate the rising popularity of this terminology, Figure 1 shows the fraction of papers published in the NBER working paper series and in top-five economics journals, respectively, that refer to the sufficient statistics approach. Panel A restricts attention to papers in the field of public economics, while Panel B includes papers from all fields of economics. ${ }^{1}$ The figure shows that the sufficient statistics terminology was rarely used until around 2010, but takes off after the publication of Raj Chetty's paper. The sharp rise in the use of sufficient statistics language over the last ten years can be seen in both working papers and in top-journal publications.

While the terminology is new, the intellectual origins of the sufficient statistics approach are very old. Economists have expressed optimal tax policy and deadweight loss in terms of demand and supply elasticities since the early days of normative public finance theory. ${ }^{2}$ Two modern developments have been pivotal for the recent influence of the approach. One is the credibility revolution in empirical research over the last two or three decades. This work has allowed for clear and credible identification of the reduced-form effects of policies using quasi-experimental

\footnotetext{
${ }^{1}$ See Currie, Kleven, and Zwiers (2020) for a detailed description of the sample selection and textual analysis methods. Because papers can refer to the sufficient statistics approach using different phrasings, the algorithm used to capture references to the approach has been designed with a view to minimize the occurences of false positives and false negatives. While it is virtually impossible to avoid errors entirely (except through a brute-force manual approach), this is not a crucial issue due to the fact that my main focus is on time trends rather than on levels. The observed trends are relatively robust to tweaks of the algorithm.

${ }^{2}$ Ramsey (1927) and Corlett and Hague (1953-1954) discussed the role of elasticities for optimal tax policy. Harberger (1964) popularized the measurement of deadweight loss using elasticity-based approximations (Harberger triangles), but he was not the first to expose the basic ideas. Hotelling (1938) provides an analysis of "Harberger triangles" before Harberger, labelling it the "classical argument" and crediting Dupuit (1844) with the underlying ideas. Hines (1999) provides a knowledgeable review tracing the intellectual history of Harberger triangles. The empirical estimation of the demand and supply elasticities relevant for deadweight loss calculations originates primarily with the large body of work by Martin Feldstein from the late 1960s onwards.
} 
research designs. The other development is a set of theoretical contributions on optimal policy and welfare measurement that have clarified the general principles under which welfare can be written as a function of reduced-form elasticities. The fundamental insight is that, because of envelope conditions from household and firm optimization, the welfare effect of small policy changes can be expressed as a fiscal externality - the impact of changed behavior on the government budget - and is therefore governed by behavioral elasticities interacted with observable tax-transfer rates. ${ }^{3}$

This paper revisits the foundations of the sufficient statistics approach, clarifies its advantages and limitations, and provides a number of generalizations. As it stands, the sufficient statistics approach relies on three key assumptions. The first assumption is that the policy change being analyzed is small, which in principle means infinitessimal or at least close enough to infinitessimal for first-order approximations to be precise. The second assumption is that government policy is the only thing that stands between the actual equilibrium and the first-best equilibrium. In other words, there are no non-government externalities or internalities that would be affected by behavioral responses to policy reforms. Finally, a third set of assumptions puts restrictions on the decision environment (including aspects such as dynamics, uncertainty, and policy instruments) and preferences (including aspects such as separability or quasi-linearity). These assumptions vary from context to context, and they govern the exact set of sufficient statistics that needs to be estimated in the given setting. ${ }^{4}$

This paper generalizes the sufficient statistics approach in all three dimensions. We cast the analysis in the language of taxation, but the framework can capture non-tax policies as well. To begin with, keeping the assumptions of small reforms and no non-government externalities, we present a sufficient statistics formula that is very general in terms of the environment and preferences. This formula holds for any type of tax system and tax reform, and it allows for dynamics and general equilibrium effects. However, the problem with this general approach is that the parameter space is very large: it includes the compensated own- and cross-price elasticities as well as the income elasticities of every good at each point in time. A sufficient statistics approach based on this many parameters is infeasible. We therefore simplify the parameter space by im-

\footnotetext{
${ }^{3}$ The fiscal externality property underlies most of the normative public finance literature, but its exact role for welfare measurement and the empirical implications have crystallized more recently. The property is crucial for the sufficiency of the elasticity of taxable income for welfare (Feldstein 1999). See Saez (2004) and Kleven and Kreiner (2005) for expositions of the general principle.

${ }^{4}$ This last set of assumptions make the sufficient statistic language slightly odd, because the elasticities are only sufficient conditional on the high-level "structural" assumptions being made.
} 
posing more structure on tax policy and preferences. An advantage of starting from a general formulation is that we can see very clearly how different combinations of assumptions generate the simple sufficient statistics formulas used in practice. This includes the Harberger-style formulas expressed in terms of a single sufficient statistic summarized by Chetty $(2009 \mathrm{~b}) .^{5}$

We then relax the other key assumptions of the approach, allowing for large reforms and for non-government distortions. It is possible to provide transparent and intuitive sufficient statistics formulas for those more general cases, but the estimation requirements increase considerably. We highlight two main results. First, it is possible to provide a trapezoid approximation of the welfare effect of large reforms, which depends on the same elasticity (or elasticities) as the smallreform formula as well as the change in the elasticity (or elasticities) created by the reform. The sufficient statistics are therefore a set of elasticity levels and elasticity changes. As we discuss, given the difficulties of reaching a consensus on elasticity levels, it may be unrealistic to hope for a consensus on elasticity changes. If so, we have to impose more structure. The simplest solution is to assume quasi-linear, iso-elastic preferences, but this is of course a fully parametric approach. Existing sufficient statistics approaches are implicitly based on such preferences, because they analyze discrete policy reforms and do not account for elasticity changes. ${ }^{6}$

Second, it is feasible to provide sufficient statistics results under a very general formulation of non-government externalities by re-defining "tax wedges" to include any uninternalized utility effect of behavioral changes. Our formulation allows for atmospheric externalities, inter-personal externalities due to social status or rat race concerns, internalities due to psychological factors, and many other aspects. ${ }^{7}$ Crucially, the redefined tax wedges are not directly observable, but have to be estimated and in fact may be harder to estimate than the behavioral elasticities. For example, while there may be some degree of consensus on the earnings elasticity at the top of the distribution, there may be less consensus on the degree to which these earnings responses represent socially productive effort as opposed to rent-seeking or rat race effects. In any case, our formulas show that the set of sufficient statistics for policy evaluation include behavioral elasticities along with externality-adjusted tax wedges on each margin of response. In the suffi-

\footnotetext{
${ }^{5}$ Starting from a general formula also allows us to compare sufficient statistics approaches to structural approaches. The latter can be viewed as an alternative way of simplifying the parameters space, namely by making parametric assumptions that reduces the high-dimensional elasticity space to a few structural primitives.

${ }^{6}$ Assuming iso-elastic preferences, the standard sufficient statistics formula still needs to be modified when reforms are large. This is because the formula has to account for the changing tax wedge over the discrete reform path.

${ }^{7}$ As a specific example, our framework also allows for the type of wage bargaining externalities modelled by Piketty, Saez, and Stantcheva (2014).
} 
cient statistics spirit, welfare evaluation does not require a fully specified model of each different market imperfection. It is sufficient to estimate "reduced-form" gaps between private and social prices in conjunction with the behavioral elasticities that we normally estimate.

The paper is organized as follows. Section 2 lays out the framework, section 3 characterizes the welfare effect of small reforms absent any non-government externalities, section 4 generalizes the analysis to large reforms, section 5 generalizes the analysis to allow for non-government distortions, and section 6 concludes.

\section{Model}

There is a continuum of individuals indexed by $i$. There is a discrete set of goods indexed by $j=0, \ldots, J$. The set of goods may include consumption and labor supply at different points in time as well as different types of consumption and labor supply at a point in time. If the setting is dynamic, goods may also include wealth at different points in time or bequests.

Utility is given by

$$
u^{i}\left(x_{0}^{i}, \ldots, x_{J}^{i}\right)=u^{i}\left(\mathbf{x}^{i}\right)
$$

The budget constraint is given by

$$
\sum_{j=0}^{J} x_{j}^{i}+T\left(x_{0}^{i}, \ldots, x_{J}^{i}\right)=y^{i}
$$

where pre-tax prices are normalized to one, or rather where we interpret $\mathbf{x}^{i}$ as a vector of pre-tax expenditures and pre-tax earnings (rather than consumption and labor supply quantities). Prices are then embodied in utility (as a function of expenditures/earnings) and any heterogeneity in prices/wage rates are accounted for in $u^{i}(.) .^{8}$ The "tax function" $T($.$) embodies all taxes and$ transfers, it may be nonlinear, and it may feature non-separabilities between different arguments. For example, if good $j$ denotes consumption at time $t$ (such that $\partial T / \partial x_{j}^{i}$ includes capital taxes) and good $j+1$ denotes labor earnings at time $t$ (so that $\partial T / \partial x_{j+1}^{i}$ includes labor taxes), then $T$ (.) is not separable in $j$ and $j+1$ under an income tax (i.e., $\partial^{2} T / \partial x_{j}^{i} \partial x_{j+1}^{i} \neq 0$ ). We will assume,

\footnotetext{
${ }^{8}$ This parsimonious specification implies that we avoid carrying price notation in the derivations. While this implies that we are taking pre-tax prices as given, there is in fact no loss of generality here. Given the assumption of perfect competition, tax-induced price changes (incidence) affect only the distribution of real incomes, they do not affect efficiency. Because the sufficient statistics approach deals with the measurement of efficiency, the results we provide are valid under any arbitrary incidence.
} 
however, that $T($.$) is piecewise linear, so that marginal tax rates are constant within brackets.$ Denoting marginal tax rates by $\partial T / \partial x_{j}^{i} \equiv \tau_{j}^{i}$, we can rewrite the budget as follows

$$
\sum_{j=0}^{J}\left(1+\tau_{j}^{i}\right) x_{j}^{i}=Y^{i}
$$

where $Y^{i} \equiv y^{i}+\sum_{j=0}^{J} \tau_{j}^{i} x_{j}^{i}-T\left(x_{0}^{i}, \ldots, x_{J}^{i}\right)$ is virtual income.

Each household maximizes utility (1) subject to the budget constraint (3). Denoting the Lagrange multiplier of this optimization program by $\lambda^{i}$, the first-order condition for $x_{j}^{i}$ is given by

$$
\frac{\partial u^{i}}{\partial x_{j}^{i}}-\lambda^{i}\left(1+\tau_{j}^{i}\right)=0,
$$

where we have used that $\partial Y^{i} / \partial x_{j}^{i}=0 .{ }^{9}$ The uncompensated demand and supply functions implied by equation (4) can be written as $x_{j}^{i}=x_{j}^{i}\left(1+\tau_{0}^{i}, \ldots, 1+\tau_{J}^{i}, Y^{i}\right)$. Indirect utility may then be defined as follows

$$
v^{i}\left(1+\tau_{0}^{i}, \ldots, 1+\tau_{J}^{i}, Y^{i}\right)=u^{i}\left(x_{0}^{i}\left(1+\tau_{0}^{i}, \ldots, 1+\tau_{J}^{i}, Y^{i}\right), \ldots, x_{J}^{i}\left(1+\tau_{0}^{i}, \ldots, 1+\tau_{J}^{i}, Y^{i}\right)\right) .
$$

The derivatives of indirect utility have well-known properties that will become useful later. The marginal utility of income $Y^{i}$ and of tax prices $1+\tau_{k}^{i}$ (taking $Y^{i}$ as given), respectively, are equal to

$$
\frac{\partial v^{i}}{\partial Y^{i}}=\lambda^{i}, \quad \frac{\partial v^{i}}{\partial\left(1+\tau_{k}^{i}\right)}=-\lambda^{i} x_{k}^{i}
$$

In deriving these results, we use the budget constraint as well as the first-order conditions. The second derivative is Roy's identity.

Finally, we also have the Slutsky decomposition, i.e.

$$
\frac{\partial x_{j}^{i}}{\partial\left(1+\tau_{k}^{i}\right)}=\frac{\partial \tilde{x}_{j}^{i}}{\partial\left(1+\tau_{k}^{i}\right)}-x_{k}^{i} \frac{\partial x_{j}^{i}}{\partial Y^{i}}
$$

where "tilde" denotes compensated demand or supply.

\footnotetext{
${ }^{9}$ Equation (4) is the optimality condition for agents locating within brackets, i.e. conditional on not bunching at a kink point between brackets. We ignore bunching at kink points throughout the analysis, because such local responses (mass points) have no first-order impact on aggregate welfare. That is, while bunching is widely studied as an empirical approach to uncover behavioral elasticities (see e.g., Saez 2010; Kleven 2016), bunching mass is not important for welfare in and of itself.
} 


\section{Welfare Effect of Small Reforms}

To study the effect of reforms, we specify tax policy as a function of a treatment parameter $\theta$, i.e. we write tax liability as $T\left(x_{0}^{i}, \ldots, x_{J}^{i}, \theta\right)$ and marginal tax rates as $\tau_{j}^{i}(\theta) \forall j$. Changes in treatment $\theta$ may capture any arbitrary set of changes in $\tau_{0}^{i}, \ldots, \tau_{J}^{i}$ and in $T($.$) , within the class of piecewise$ linear policies. ${ }^{10}$ This section focuses on small reforms $(d \theta \approx 0)$, while the next section generalizes the analysis to large reforms.

We start by calculating the money-metric effect on utility of such policy reforms, i.e. $\frac{d v^{i} / d \theta}{\lambda^{i}}$. We have

$$
\frac{d v^{i}}{d \theta}=\sum_{j=0}^{J} \frac{\partial v^{i}}{\partial\left(1+\tau_{j}^{i}\right)} \frac{d \tau_{j}^{i}}{d \theta}+\frac{\partial v^{i}}{\partial Y^{i}} \frac{d Y^{i}}{d \theta} .
$$

Using equation (6), this may be rewritten to

$$
\frac{d v^{i} / d \theta}{\lambda^{i}}=-\sum_{j=0}^{J} x_{j}^{i} \frac{d \tau_{j}^{i}}{d \theta}+\frac{d Y^{i}}{d \theta}
$$

From the definition of virtual income, i.e. $Y^{i}(\theta) \equiv y^{i}+\sum_{j=0}^{J} \tau_{j}^{i}(\theta) x_{j}^{i}-T\left(x_{0}^{i}, \ldots, x_{J}^{i}, \theta\right)$, we have

$$
\frac{d Y^{i}}{d \theta}=\sum_{j=0}^{J} \frac{d \tau_{j}^{i}}{d \theta} x_{j}^{i}-\frac{\partial T^{i}}{\partial \theta}
$$

Inserting (10) into (9), we obtain

$$
\frac{d v^{i} / d \theta}{\lambda^{i}}=-\frac{\partial T^{i}}{\partial \theta}
$$

Hence, the utility effect of any arbitrary, small reform equals the mechanical revenue effect. This central result follows from envelope conditions (as embodied in equation 6) and the assumption of no other externalities than those operating through the government budget.

To move from individual welfare to social welfare, we specify a social welfare objective

$$
W(\theta)=\int_{i} \omega^{i} v^{i}(\theta) d i+\mu \int_{i} T^{i}(\theta) d i
$$

where $\omega^{i}$ is a Pareto weight on individual $i$, and $\mu$ is the marginal value of government revenue.

\footnotetext{
${ }^{10}$ The same flexible specification of policy reform was used by Kleven and Kreiner (2002, 2006), Eissa, Kleven, and Kreiner $(2006,2008)$, and Hendren (2016).
} 
Differentiating $W(\theta)$ and using equation (11), we obtain

$$
\frac{d W / d \theta}{\mu}=\int_{i}\left[\frac{d T^{i}}{d \theta}-g^{i} \frac{\partial T^{i}}{\partial \theta}\right] d i=\int_{i}[\underbrace{\left(\frac{d T^{i}}{d \theta}-\frac{\partial T^{i}}{\partial \theta}\right)}_{\text {efficiency }}+\underbrace{\left(1-g^{i}\right) \frac{\partial T^{i}}{\partial \theta}}_{\text {equity }}] d i
$$

where $g^{i} \equiv \frac{\omega^{i} \lambda^{i}}{\mu}$ denotes the social marginal welfare weight on individual $i$. The social welfare weights averages to 1 in the population, and their variation across individuals summarizes the government's preferences for equity. ${ }^{11}$ Equation (13) splits the total welfare effect into an efficiency effect (first term on the right-hand side) and an equity effect (second term on the righthand side), the latter being governed by $g^{i}$. Absent equity concerns $\left(g^{i}=1 \forall i\right)$, the second term equals zero. The sufficient statistics approach is typically about the measurement of efficiency, not equity, and we will keep the same focus here. It is therefore useful to highlight the result on efficiency as a proposition:

Proposition 1 (Fiscal Externality). The effect of any small tax reform on economic efficiency equals

$$
\left.\frac{d W / d \theta}{\mu}\right|_{g^{i}=1}=\int_{i}\left[\frac{d T^{i}}{d \theta}-\frac{\partial T^{i}}{\partial \theta}\right] d i
$$

namely the difference between the total and mechanical revenue effects, which corresponds to the behavioral revenue effect ("fiscal externality").

The efficiency effect of any small reform of the tax-transfer system equals the fiscal externality from behavioral responses to the reform. ${ }^{12}$ The intuition for this result is simple. Because agents are optimizing and there are no non-tax externalities, behavioral responses to small reforms have no first-order effects on utility. The only first-order effect comes from an externality that operates through the government budget: When agents adjust behavior to avoid higher taxes, they create tax revenue leaks that impose a fiscal externality on the rest of the population (the potential transfers they can receive are now lower).

We have cast the analysis in the language of taxation, but the underlying envelope theorem logic extends to any form of policy or intervention given the same general assumptions. The

\footnotetext{
${ }^{11}$ Throughout the paper, we cast the analysis in the language of taxes/transfers and equity, but everything can be restated in the language of social insurance and consumption smoothing. In that case, $W(\theta)$ would represent expected utility over different states of the world $i$, and the weights $g^{i}$ capture the benefits from consumption smoothing across good and bad states.

${ }^{12}$ See also Kleven and Kreiner $(2005,2006)$ and Eissa, Kleven, and Kreiner $(2006,2008)$ for detailed analyses of this point.
} 
logic of Proposition 1 underscores much of the normative public finance literature, including optimal taxation (Diamond and Mirrlees 1971; Diamond 1998; Saez 2001), deadweight loss measurement (Harberger 1964; Browning 1987; Feldstein 1999; Goulder and Williams 2003; Kleven and Kreiner 2005; Eissa, Kleven, and Kreiner 2006, 2008; Chetty 2009a), the marginal cost of public funds (Browning 1976; Slemrod and Yitzhaki 1996, 2001; Kleven and Kreiner 2006), social insurance (Baily 1978; Chetty 2006, 2008; Chetty and Finkelstein 2013; Kolsrud, Landais, Nilsson, and Spinnewijn 2018), welfare programs (Finkelstein and Notowidigdo 2019), stimulus spending (Michaillat and Saez 2019), and transportation infrastructure investments (Donaldson 2018). This list is far from exhaustive; there are many other existing and potential future applications of the approach. Although the theoretical property was always there behind the curtains, the crystallization of the fundamental principle — including its implications for empirical work has emerged more clearly over the last couple of decades.

Leaving aside any potential concerns about the underlying assumptions, should we conclude the theoretical analysis here and focus on the fiscal externality as the target for empirical work? Hendren (2016) argues that we should, re-casting the fiscal externality in different language. Specifically, using the tax function $T\left(x_{0}^{i}, \ldots, x_{J}^{i}, \theta\right)$, we can rewrite equation (14) as

$$
\left.\frac{d W / d \theta}{\mu}\right|_{g^{i}=1}=\int_{i}\left[\sum_{j=0}^{J} \tau_{j}^{i} x_{j}^{i} \frac{d \log \left(x_{j}^{i}\right)}{d \theta}\right] d i
$$

where $\frac{d \log \left(x_{j}^{i}\right)}{d \theta}$ is labelled the "policy elasticity" by Hendren (2016). He argues that such policy elasticities should be the object of interest for applied welfare analysis. To be precise, given we do not estimate individual-level elasticities, the object of interest for empirical studies would be $\varepsilon_{j}^{P}=\int_{i} \tau_{j}^{i} x_{j}^{i} \frac{d \log \left(x_{j}^{i}\right)}{d \theta} d i$, i.e. the revenue-weighted average policy elasticity for each good $j$.

Two remarks on such an approach are worth making, a pedantic one and a substantive one. First, the pedantic remark:

Remark 1 (Elasticities are Irrelevant for Assessing Actual Reform). When measuring the welfare effect of an actual policy reform, it is unnecessary to estimate elasticities. Consider the policy treatments $\theta_{0}, \theta_{1}$ where $d \theta=\theta_{1}-\theta_{0} \approx 0$, and assume random assignment to treatments. The welfare effect can be 
estimated as

$$
\begin{aligned}
& \mathrm{E}\left\{T\left(x_{0}^{i}\left(\theta_{1}\right), \ldots, x_{J}^{i}\left(\theta_{1}\right), \theta_{1}\right) \mid i \in \theta_{1}\right\}-\mathrm{E}\left\{T\left(x_{0}^{i}\left(\theta_{0}\right), \ldots, x_{J}^{i}\left(\theta_{0}\right), \theta_{1}\right) \mid i \in \theta_{1}\right\} \\
= & \mathrm{E}\left\{T\left(x_{0}^{i}\left(\theta_{1}\right), \ldots, x_{J}^{i}\left(\theta_{1}\right), \theta_{1}\right) \mid i \in \theta_{1}\right\}-\mathrm{E}\left\{T\left(x_{0}^{i}\left(\theta_{0}\right), \ldots, x_{J}^{i}\left(\theta_{0}\right), \theta_{1}\right) \mid i \in \theta_{0}\right\} .
\end{aligned}
$$

The assumption of random assignment is not important for the conceptual point (absent randomization one would use a different estimator). Whatever the estimation approach, if the sole objective is to measure the welfare effect of an actual reform experiment, it is unnecessary to estimate elasticities or sufficient statistics. The outcome of interest is directly estimable. However, evaluating actual reforms is almost never the sole objective of policy debate or academic discourse. Assessing policy reform is instead about comparing different counterfactual scenarios, which leads to the second and substantive remark:

Remark 2 (Policy Elasticities). Consider a reform experiment $R=\left\{\frac{d \tau_{0}^{i}}{d \theta}, \ldots, \frac{d \tau_{J}^{i}}{d \theta}, \frac{\partial T^{i}}{\partial \theta}\right\}_{i \in I}$. Because policy elasticities are functions of $R$, they can be used only to measure the welfare effect of the actually implemented experiment $R$ (compared to the counterfactual of no reform). They cannot be used to assess the welfare effect of any other counterfactual reform that could be implemented.

Under the policy elasticity approach to empirical research, economists would know only the aggregate welfare effect of historical reforms. With this information alone, we would not be able to provide any advice on future reforms, unless they exactly replicate or reverse historical reforms. The basic limitation of policy elasticities is that they are externally invalid by construction. To assess policy design, we have to express the fiscal externality in terms of price and income elasticities that are externally valid. ${ }^{13}$

To derive a sufficient statistics formula based on (potentially) externally valid elasticities, we go back to the fiscal externality expression in equation (14). Using the tax function $T\left(x_{0}^{i}, \ldots, x_{J}^{i}, \theta\right)$, this can be rewritten as

$$
\left.\frac{d W / d \theta}{\mu}\right|_{g^{i}=1}=\int_{i} \sum_{j=0}^{J} \tau_{j}^{i}\left[\sum_{k=0}^{J} \frac{\partial x_{j}^{i}}{\partial\left(1+\tau_{k}^{i}\right)} \frac{d \tau_{k}^{i}}{d \theta}+\frac{\partial x_{j}^{i}}{\partial Y^{i}} \frac{d Y^{i}}{d \theta}\right] d i .
$$

\footnotetext{
${ }^{13}$ Another important reason for estimating such elasticities is that they provide a normalized measure of behavioral response that can be compared across settings, thus allowing researchers to better gauge the magnitude and credibility of different estimates. This is particularly important when one is concerned about possible bias from confounders. For example, Kleven (2020) uses elasticity calculations to assess the credibility of difference-in-differences estimates of labor supply responses to the Earned Income Tax Credit (EITC).
} 
Moreover, using $\frac{d Y^{i}}{d \theta}=\sum_{k=0}^{J} \frac{d \tau_{k}^{i}}{d \theta} x_{k}^{i}-\frac{\partial T^{i}}{\partial \theta}$, the Slutsky decomposition, and rearranging terms, we may state the following:

Proposition 2 (Sufficient Statistics for Small Reforms). The effect of any small tax reform on economic efficiency can be written as

$$
\left.\frac{d W / d \theta}{\mu}\right|_{g^{i}=1}=\int_{i} \sum_{j=0}^{J}\left[\sum_{k=0}^{J} \tau_{j}^{i} x_{j}^{i} \varepsilon_{j k}^{i} \frac{d \tau_{k}^{i} / d \theta}{1+\tau_{k}^{i}}-\tau_{j}^{i} x_{j}^{i} \eta_{j}^{i} \frac{\partial T^{i} / \partial \theta}{Y^{i}}\right] d i
$$

where $\varepsilon_{j k}^{i} \equiv \frac{\partial \tilde{x}_{j}^{i}}{\partial\left(1+\tau_{k}^{i}\right)} \frac{1+\tau_{k}^{i}}{\tilde{x}_{j}^{i}}$ is the Hicksian price elasticity of good $j$ wrt. the price on good $k$, and $\eta_{j}^{i} \equiv$ $\frac{\partial x_{j}^{i}}{\partial Y^{i}} \frac{Y^{i}}{x_{j}^{i}}$ is the income elasticity of good $j$. Therefore, conditional on a set of observables (tax parameters, expenditure and earnings levels), the sufficient statistics for evaluating reform are $\left\{\varepsilon_{j k}^{i}, \eta_{j}^{i}\right\}_{\forall j, k, i}$.

This formula is completely general given the assumptions of small reforms and no non-policy imperfections. It is a general equilibrium result as it accounts for distortions in all markets and allows for any possible cross-effects between markets. We take prices as given in the derivation, but incorporating price changes (tax incidence) would not change the formula. Under the assumption of perfect competition, general equilibrium price changes redistribute across agents, but do not impact economic efficiency.

There is a problem, however. Because the goods vector in general includes different types of consumption and labor supply over time (i.e., $j$ captures both goods type and time), the parameter space is in general very large. The sufficient statistics approach is therefore infeasible without more structure. To make progress, we have to reduce the dimensionality of the problem by either (i) restricting the tax policy space or (ii) restricting behavioral responses. Most sufficient statistics approaches do both, although this is often left implicit. By starting from a general formulation, we are able to see exactly how different sets of assumptions lead to simple sufficient statistics expressions. We consider this in the next section.

\subsection{Many Roads Lead To Harberger}

To begin with, consider the baseline model presented in Chetty (2009b). Three assumptions are made there: (i) utility is quasi-linear, (ii) only one good is taxed, and (iii) the tax is linear. The first assumption implies $\eta_{j}^{i}=0 \forall j, i$. Assuming that good 0 is the taxed good, equation (18) simplifies 
to

$$
\left.\frac{d W / d \theta}{\mu}\right|_{g^{i}=1}=\bar{\varepsilon}_{0} \cdot \frac{\tau_{0}}{1+\tau_{0}} \cdot \frac{d \tau_{0}}{d \theta},
$$

where $\bar{\varepsilon}_{0} \equiv \int_{i}\left[x_{0}^{i} \varepsilon_{00}^{i}\right] d i$ is the demand-weighted average Hicksian elasticity in the population. This is a Harberger-style formula for the marginal deadweight loss of taxation in which $\bar{\varepsilon}_{0}$ is the sufficient statistic for welfare analysis. ${ }^{14}$ The sense in which $\bar{\varepsilon}_{0}$ is "sufficient" is of course conditional on the underlying assumptions. But it is possible to consider alternative restrictions on tax policy space or preferences that give rise to a similar formula.

Keeping the assumption of quasi-linearity, we can relax the assumption that only one good is taxed. Assume that goods $0, \ldots, J_{0}$ are taxed at rate $\tau_{0}$, while goods $J_{0}+1, \ldots, J$ are taxed at rate $\tau_{1}$. We may then normalize $\tau_{1}$ to zero (and adjust $\tau_{0}$ accordingly) without loss of generality. In this case we obtain the Harberger formula (19) once more, except that we have to redefine the elasticity as $\bar{\varepsilon}_{0} \equiv \int_{i}\left[\sum_{j=0}^{J_{0}} \sum_{k=0}^{J_{0}} x_{j}^{i} \varepsilon_{j k}^{i}\right] d i$. This is a demand-weighted average elasticity across goods $0, \ldots, J_{0}$ (instead of only good 0 ) with respect to the tax rate $\tau_{0}$ on all those goods (instead of only on good 0). Again, a single elasticity is sufficient for welfare analysis, but the elasticity is different than before.

To see the economic distinction between the two cases just described, consider the taxation of labor income as an example. The first case may be interpreted as a static model in which good 0 is labor supply and goods $1, \ldots, J$ are different consumption goods. The second case may be interpreted as a dynamic model in which goods $0, \ldots, J_{0}$ are labor supplies in different periods (taxed at a constant rate over time), while goods $J_{0}+1, \ldots, J$ are consumption in different periods (taxed at a constant rate over time). ${ }^{15}$ These two models give rise to the same Harberger formula by reinterpreting the static earnings-weighted labor supply elasticity to a lifetime earnings-weighted labor supply elasticity with respect to a permanent tax.

Alternatively, the second case may be interpreted as capturing multi-dimensional labor supply choices (hours worked, effort, occupation, training, etc.), which jointly determine labor earnings taxed at rate $\tau_{0}$. In this case, the sufficient statistic $\bar{\varepsilon}_{0} \equiv \int_{i}\left[\sum_{j=0}^{J_{0}} \sum_{k=0}^{J_{0}} x_{j}^{i} \varepsilon_{j k}^{i}\right] d i$ is the elasticity of total labor income governed by all the underlying margins of behavior, or the elasticity of taxable income in the language of Feldstein $(1995,1999)$. If we allow for dynamics, this is the life-

\footnotetext{
${ }^{14}$ Unlike Harberger-triangle approximations, equation (19) is an exact formula that holds for any tax rate $\tau_{0}$ and any functional form for preferences (given quasi-linearity). Traditional Harberger-triangle formulas assume either that taxes are small or that demand functions are linear.

${ }^{15}$ The assumption of uniform consumption taxation rules out capital taxes.
} 
time elasticity of taxable income with respect to a permanent income tax. This result generalizes Feldstein's analysis. ${ }^{16}$

There are other ways of obtaining the simple sufficient statistics formula in (19). If we assume both quasi-linearity $\left(\eta_{j}^{i}=0\right)$ and no cross-effects $\left(\varepsilon_{j k}^{i}=0\right.$ for $\left.j \neq k\right)$, then the result is obtained when only one tax is changing (and this tax is linear). In other words, by adding the assumption of no cross-effects, we can relax the assumption that only one good is taxed to an assumption that only one tax is changing in the reform.

By making a stronger assumption on the tax system, it is possible to obtain a simple Harbergerstyle formula without quasi-linear preferences. Specifically, under a linear proportional tax system (no lump-sum taxes or transfers), we have $T^{i}=\sum_{k=0}^{J} \tau_{k}(\theta) x_{k}^{i}$ and therefore $\frac{\partial T^{i}}{\partial \theta}=\sum_{k=0}^{J} \frac{d \tau_{k}}{d \theta} x_{k}^{i}$. Inserting this into (18) and using (7), we obtain a welfare formula that depends only on price elasticity terms, but where those price elasticities are Marshallian rather than Hicksian. Assuming that goods $0, \ldots, J_{0}$ are taxed at rate $\tau_{0}$ while the rest of the goods are untaxed, we obtain the Harberger-style formula (19) with $\bar{\varepsilon}_{0}$ being a Marshallian elasticity.

The fundamental challenge we face is that a general sufficient statistics approach (one based on equation 18) would rely on too many parameters to be feasible. Actual sufficient statistics approaches simplify the parameter space — often to just one parameter - by making high-level assumptions about preferences and tax policy. The alternative is to simplify the parameter space by assuming an explicit parametric form for $u($.$) , i.e. to take a "structural approach."$

It is useful to contrast the sufficient statistics and structural approaches in a specific example. Consider the case where the goods vector includes labor supplies and consumption in different periods, i.e. $u=u\left(l_{0}, \ldots, l_{T} ; c_{0}, \ldots, c_{T}\right)$. Assuming that $l_{t}$ and $c_{t}$ are taxed at constant rates over time, we can express the welfare effect of tax reform as equation (19) where the sufficient statistic is the lifetime earnings-weighted labor supply elasticity. The assumption of a constant tax rate on consumption rules out capital taxes. Alternatively, we may assume that $u($.$) has a tractable form.$ We might consider, say, a nested CES function $u\left(f\left(c_{0}, l_{0}\right), \ldots, f\left(c_{T}, l_{T}\right)\right)$ with three parameters: an intratemporal elasticity of substitution between consumption and labor $\sigma_{1}$, an intertemporal elasticity of substitution $\sigma_{2}$, and a discount factor $\delta$. These three parameters (along with prices) control all the sufficient statistics in equation (18). We no longer have to make restrictions on tax

\footnotetext{
${ }^{16}$ The reason why we can express efficiency in terms of a single sufficient statistic even in the presence of cross-effects (such as shifting responses) is that all margins of behavior are taxed either at the rate $\tau_{0}$ or not at all. With cross-effects (shifting) between bases that are taxed at different non-zero rates, we need to estimate more parameters. Equation (18) provides the general formula. Saez (2004), Saez, Slemrod, and Giertz (2012), and Piketty, Saez, and Stantcheva (2014) consider an example with two bases taxed at different (non-zero) rates and shifting between the two.
} 
policy space, but can be more general in this dimension. This includes allowing for capital taxes.

Besides the differences in assumptions, a crucial difference between these two approaches lies in the data requirements. The sufficient statistics approach calls for the estimation of a lifetime earnings-weighted labor supply elasticity. It is challenging to find the tax variation and data allowing for the estimation of this long-run parameter. By making parametric assumptions, the structural approach allows for the estimation of welfare effects using shorter-run variation in the data. As long as the tax variation is rich enough to separately identify the structural primitives $\left(\sigma_{1}, \sigma_{2}, \delta\right)$, the model can generate the full lifecycle effects necessary to calculate welfare. Of course, these calculations are meaningful only if the parametric assumptions are correct.

The preceding discussion highlights that the key trade-off when choosing methodology is between data requirements and parametric assumptions. How to strike this trade-off depends on the research question and data availability. It is worth mentioning that, in practice, a common difference between the sufficient statistics and structural approaches is that the former is based on exogenous (e.g. quasi-experimental) variation, while the latter is based on observational and potentially endogenous variation. However, this divide is largely independent of the deeper conceptual trade-offs discussed here; it reflects cultural differences across research strands. The structural approach could (and should) target quasi-experimental moments. ${ }^{17}$

\subsection{Tax-Base Changing Reforms}

A key feature of many tax reforms is that they change both tax rates and tax bases. The framework is sufficiently general to analyze tax base changes. For example, base broadening corresponds to introducing a positive tax rate on some good $k$ that was initially taxed at rate zero, i.e. $\frac{d \tau_{k}}{d \theta}>0$ where $\tau_{k}=0$ initially. Typically, the newly introduced good is taxed at the same rate as a set of other goods already in the tax base, i.e. $\frac{d \tau_{k}}{d \theta}=\tau_{k^{\prime}}$ where $k^{\prime}$ is a good already in the tax base. If the initial tax base is taxed at a large rate, $\tau_{k^{\prime}}>>0$, then a base broadening reform is necessarily a large reform. Therefore, the small-reform assumption made thus far is more tenuous when considering tax base changing reforms, and so the generalization to large reforms in the next section is important. Nevertheless, it is possible to achieve a number of key insights on base broadening within the small-reform framework as we now show.

To simplify, we focus on situations where preferences are quasi-linear and taxes are linear. We

\footnotetext{
${ }^{17}$ For example, Jakobsen, Jakobsen, Kleven, and Zucman (2020) develops a structural, quasi-experimental approach for studying the long-run effects of wealth taxes, an area where a sufficient statistics approach is not feasible in practice.
} 
start by considering a case where only good 0 is taxed initially, and where the reform changes the tax rate on good 0 and brings good 1 into the tax base. In this case, the general welfare formula (18) simplifies to

$$
\left.\frac{d W / d \theta}{\mu}\right|_{g^{i}=1}=\bar{\varepsilon}_{0} \cdot \frac{\tau_{0}}{1+\tau_{0}} \cdot \frac{d \tau_{0}}{d \theta}+\bar{\varepsilon}_{01} \cdot \frac{\tau_{0}}{1+\tau_{1}} \cdot \frac{d \tau_{1}}{d \theta},
$$

where $\bar{\varepsilon}_{0} \equiv \int_{i}\left[x_{0}^{i} \varepsilon_{00}^{i}\right] d i$ and $\bar{\varepsilon}_{01} \equiv \int_{i}\left[x_{0}^{i} \varepsilon_{01}^{i}\right] d i$. If the initial good in the tax base and the newly introduced good are substitutes (complements), then $\bar{\varepsilon}_{0}$ and $\bar{\varepsilon}_{01}$ have the opposite (same) signs.

According to conventional wisdom in public finance, it is better to collect a given amount of revenue by taxing broad base at a low rate than by taxing a narrow base at a high rate. The result in equation (20) formalizes the condition under which this "folk theorem" is true. To see this, consider a reform that lowers the tax rate on the existing base $\left(\frac{d \tau_{0}}{d \theta}<0\right)$ and at the same time broadens the base $\left(\frac{d \tau_{1}}{d \theta}>0\right)$. The own-price elasticity $\bar{\varepsilon}_{0}$ is negative, while the cross-price elasticity $\bar{\varepsilon}_{01}$ is positive (negative) if the two goods are substitutes (complements). In the case of substitutability, both terms of equation (20) are positive and the base-broadening reform necessarily increases efficiency. In the case of complementarity, we have offsetting effects on efficiency. ${ }^{18}$ Therefore, we are able to re-state the conventional wisdom in a precise and intuitive fashion: it is always efficient to broaden the tax base and lowering the tax rate if the existing and new elements of the tax base are substitutes, but not necessarily if they are complements. This is related to the classic logic of Corlett and Hague (1953-1954). ${ }^{19}$

To see this point more starkly, assume for simplicity that goods 0 and 1 are the only goods in the economy. In this case, homogeneity of degree zero of compensated demands implies $\bar{\varepsilon}_{01}=$ $-\bar{\varepsilon}_{0}$ (using Euler's Theorem). Hence, equation (20) can be rewritten as

$$
\left.\frac{d W / d \theta}{\mu}\right|_{g^{i}=1}=\bar{\varepsilon}_{0} \cdot\left\{\frac{\tau_{0}}{1+\tau_{0}} \cdot \frac{d \tau_{0}}{d \theta}-\frac{\tau_{0}}{1+\tau_{1}} \cdot \frac{d \tau_{1}}{d \theta}\right\}
$$

We arrive once more at a welfare formula written in just one sufficient statistic, $\bar{\varepsilon}_{0}$, but the tax rate term (in curly brackets) with which we multiply that elasticity is different. Because both the elasticity and the tax rate term are negative, the base broadening reform always increases effi-

\footnotetext{
${ }^{18}$ In this case, the net effect on efficiency depends, besides the strength of complementarity $\bar{\varepsilon}_{01}$, on the magnitude of tax rate changes $\frac{d \tau_{0}}{d \theta}, \frac{d \tau_{1}}{d \theta}$. If the reform is revenue neutral, the latter depends on the budgets shares of the different goods.

${ }^{19}$ While our example was phrased in terms of goods (demands), the result applies equally to incomes (supplies). For example, if the goods are two different labor income components $l_{0}$ and $l_{1}$, we have $x_{0}=-l_{0}$ and $\tau_{0}=-\tau_{l_{0}}$ and similarly for good 1 . The own-wage elasticity $\bar{\varepsilon}_{0}$ is negative (because good zero is minus labor supply) and the cross-wage elasticity $\bar{\varepsilon}_{01}$ is positive if the two labor components are substitutes. Accounting for these signs, a similar reasoning applies to base broadening in income taxation.
} 
ciency. This reflects the fact that, with only two goods in the economy, these goods are necessarily substitutes.

Another way of looking at the importance of tax bases is to compare the welfare effect of tax rate increases under a narrow base and under a broad base, respectively. If only good 0 is taxed (narrow base), then the welfare effect is given by the Harberger formula (19). If both goods 0 and 1 are taxed at rate $\tau$ (broad base), then the welfare effect (18) can be written as

$$
\left.\frac{d W / d \theta}{\mu}\right|_{g^{i}=1}=\left[\bar{\varepsilon}_{0}+2 \cdot \bar{\varepsilon}_{01}+\bar{\varepsilon}_{1}\right] \cdot \frac{\tau}{1+\tau} \cdot \frac{d \tau}{d \theta},
$$

where we use that $x_{0}^{i} \varepsilon_{01}^{i}=x_{1}^{i} \varepsilon_{10}^{i}$ due to Slutsky symmetry and the fact that the two goods are taxed at the same rate $\tau$.

Comparing the narrow-base formula (19) to the broad-base formula (22), we see that there are two key differences. First, the tax rate is lower under the broad base for a given revenue requirement (conditional on being below the Laffer point). This makes the efficiency cost of tax increases smaller under the broad base. Second, the elasticity term is different under the broad base. The broad-base elasticity $\bar{\varepsilon}_{0}+2 \cdot \bar{\varepsilon}_{01}+\bar{\varepsilon}_{1}$ is smaller or larger than the narrow-base elasticity $\bar{\varepsilon}_{0}$ depending on the extra components included in the base. The broad-base elasticity may be smaller (in absolute value) when substitutes are included in the base (in which case $\bar{\varepsilon}_{01}$ has the opposite sign of $\left.\bar{\varepsilon}_{0}, \bar{\varepsilon}_{1}\right) .{ }^{20}$ On the other hand, the broad-base elasticity is larger when complements are included. Again, this connects the effects of base broadening with classic Corlett-Hague reasoning.

\subsection{An Optimal Tax Trick}

Technically, it is just a small step from the tax reform formulas presented above to optimal taxation. A necessary condition for an optimal tax system is that there exists no small reform that can increase welfare. ${ }^{21}$ Therefore, we must have $\frac{d W}{d \theta}=0$ for any $\theta$. From equation (13), this implies

$$
\left.\frac{d W / d \theta}{\mu}\right|_{g^{i}=1}=\int_{i}\left(g^{i}-1\right) \frac{\partial T^{i}}{\partial \theta} d i
$$

\footnotetext{
${ }^{20}$ For example, if goods 0 and 1 are the only two goods in the economy, they are necessarily substitutes. In this case, we have $\bar{\varepsilon}_{01}=\bar{\varepsilon}_{10}=-\bar{\varepsilon}_{1}$ (using Slutsky symmetry, identical tax rates, and homogeneity of degree zero of compensated demands). This gives a broad-base elasticity equal to $\bar{\varepsilon}_{0}-\bar{\varepsilon}_{1}$, which is smaller in absolute value than the narrow-base elasticity.

${ }^{21}$ See Saez (2001) and Piketty and Saez (2013) for detailed expositions of the tax reform approach to deriving optimal tax rates.
} 
where the left-hand side is the efficiency effect and the right-hand side is the equity effect. For example, in the special case underlying the Harberger-style result (19), we can rewrite this to

$$
\frac{\tau_{0}}{1+\tau_{0}}=\frac{\int_{i}\left(g^{i}-1\right) x_{0}^{i} d i}{\bar{\varepsilon}_{0}},
$$

where the numerator corresponds to the covariance between social welfare weights $g^{i}$ and demand for the taxed good $x_{0}^{i} \cdot{ }^{22}$ If there are several goods taxed at rate $\tau_{0}$, then $x_{0}^{i}$ is replaced by the total demand for the taxed goods. This formula is a classic inverse elasticity rule trading off efficiency losses (denominator) against equity gains (numerator).

Results such as (24) make it tempting to say - and many papers do - that $\bar{\varepsilon}_{0}$ is a sufficient statistic for optimal taxation. However, this is a "trick", because the fact that we are considering the optimal tax system changes the game. The condition holds at the optimum, and therefore $\bar{\varepsilon}_{0}$ is the elasticity at the optimal point. A priori this can be any point. Therefore, while it is formally correct that $\bar{\varepsilon}_{0}$ at the optimal point is a sufficient statistic, knowing this statistic requires global knowledge of demand functions. This implies a fully structural approach rather than a sufficient statistic approach. ${ }^{23}$ Many optimal tax papers assume iso-elastic preferences, which is a specific parametric form. Despite this limitation, it remains useful to express optimal tax rules in terms of elasticities, because of the intuition this provides and because iso-elastic preferences may be a natural benchmark.

\section{Welfare Effect of Large Reforms}

The sufficient statistic approach is exact only for infinitessimal reforms, but real-world reforms are never infinitessimal. If they were, we would not be very interested in them. How small do reforms have to be for the sufficient statistic approach to be informative? Can we formulate a sufficient statistic approach for larger reforms? These are important questions, because the alternative to assessing large reforms - a fully structural approach - is less transparent and

\footnotetext{
${ }^{22}$ To see this, recall that the social welfare weights average to 1 in the population $\left(\mathrm{E}\left[g^{i}\right]=1\right)$, implying that the numerator corresponds to $\mathrm{E}\left[g^{i} x_{0}^{i}\right]-\mathrm{E}\left[g^{i}\right] \mathrm{E}\left[x_{0}^{i}\right]$.

${ }^{23}$ Motivated by these challenges, Kleven (2004) develops a different approach to optimal taxation in which the optimal policy can be expressed in terms of potentially observable proxies for the (hard-to-estimate) price elasticities. Based on Gary Becker's theory of the allocation of time, these proxies are factor shares in household production/consumption activities. One might be tempted to call this a "sufficient statistics for the sufficient statistics" approach. At the same time, it is a more structural approach as it relies on the Becker household production model.
} 
relies on potentially strong parametric assumptions.

When reforms are large, the existing sufficient statistic approach corresponds to a first-order Taylor approximation of social welfare. Therefore, a natural way to improve the welfare analysis of large reforms would be to consider higher-order Taylor approximations. While we consider such Taylor approximations later, we start by developing another approach to the welfare analysis of large reforms.

As before, we specify the high-dimensional policy space in terms of a treatment parameter $\theta$, i.e. we write the tax function as $T^{i}=T\left(x_{0}^{i}, \ldots, x_{J}^{i}, \theta\right)$ and the marginal tax rates as $\tau_{j}^{i}(\theta)$ for all $i, j$. Specifically, by defining the marginal tax rates as $\tau_{j}^{i}+\theta \Delta \tau_{j}^{i}$ where $\Delta \tau_{j}^{i}$ is the reform-induced tax rate change, the pre-reform policy corresponds to $\theta_{0}=0$ and the post-reform policy corresponds to $\theta_{1}=1$. The tax rate changes $\Delta \tau_{j}^{i}$ may be large.

We start from the observation that the discrete welfare change between $\theta_{0}=0$ and $\theta_{1}=1$ can be written as the integral of the marginal welfare changes between those two points, i.e.

$$
\Delta W=W(1)-W(0)=\int_{0}^{1} \frac{d W}{d \theta} d \theta
$$

Because we have previously characterized the marginal welfare changes under very general conditions (in Propositions 1-2), we are able to provide an (almost) exact formula for the welfare effect of large reforms in terms of elasticities. Focusing on the pure efficiency effect, we have Proposition 3 (Sufficient Statistics for Large Reforms: Almost Exact). The efficiency effect of a discrete reform from regime $\theta_{0}=0$ to regime $\theta_{1}=1$ can be written as

$$
\left.\frac{\Delta W}{\mu_{0}}\right|_{g^{i}=1}=\left.\int_{0}^{1} \frac{d W / d \theta}{\mu_{0}}\right|_{g^{i}=1} d \theta
$$

where $\mu_{0}=\mu(0)$ is the marginal value of government revenue at the initial policy $\theta_{0}=0$, and where

$$
\begin{aligned}
\left.\frac{d W / d \theta}{\mu_{0}}\right|_{g^{i}=1} \approx & \int_{i} \sum_{j=0}^{J}\left[\sum_{k=0}^{J}\left(\tau_{j}^{i}+\theta \Delta \tau_{j}^{i}\right) x_{j}^{i}(\theta) \varepsilon_{j k}^{i}(\theta) \frac{\Delta \tau_{k}^{i}}{1+\tau_{k}^{i}+\theta \Delta \tau_{k}^{i}}\right. \\
& \left.-\left(\tau_{j}^{i}+\theta \Delta \tau_{j}^{i}\right) x_{j}^{i}(\theta) \eta_{j}^{i}(\theta) \frac{\partial T^{i} / \partial \theta}{Y^{i}(\theta)}\right] d i .
\end{aligned}
$$

The elasticities $\varepsilon_{j k}^{i}, \eta_{j}^{i}$ and demands $x_{j}^{i}$ are measured at regime $\theta \in(0,1)$. Equation (27) is an approximation only because it assumes $\mu_{0} \approx \mu(\theta)$ between $\theta_{0}=0$ and $\theta_{1}=1$.

This proposition provides an almost exact formula for the welfare effect of large reforms as a 
function of elasticities. The formula is too general to be useful for policy evaluation, but it does highlight the dimensions in which the standard sufficient statistics approach may get it wrong. The standard approach measures the fiscal externality based on the initial tax wedge interacted with the initial elasticity, while the exact formula depends on the path of wedges and elasticities between $\theta_{0}=0$ and $\theta_{1}=1$. Therefore, the potential sources of error come from changing wedges and changing elasticities over the reform path.

To obtain additional insight, we simplify the analysis in two dimensions. First, instead of considering the exact integral of marginal welfare effects, we consider a trapezoid approximation of this integral. Specifically, equation (25) can be approximated as

$$
\Delta W=\int_{0}^{1} \frac{d W}{d \theta} d \theta \approx \frac{1}{2}\left\{\frac{d W(0)}{d \theta}+\frac{d W(1)}{d \theta}\right\}
$$

Compared to the standard sufficient statistics approach (which assumes that the marginal welfare effect $d W / d \theta$ is constant over the reform path), the trapezoid approximation in (28) allows $d W / d \theta$ to change, but in a linear fashion. The error made by this approximation depends on the degree of convexity or concavity of the marginal welfare effect.

Second, we simplify the analysis by imposing more structure on preferences and tax policy. Consider the special case underlying the standard sufficient statistics formula (19) for small reforms. This special case assumes quasi-linear utility and a single tax rate $\tau_{0}$ on taxed goods. In this case, we have

$$
\left.\frac{\Delta W}{\mu_{0}}\right|_{g^{i}=1} \approx \frac{1}{2}\left\{\bar{\varepsilon}_{0}(0) \cdot \frac{\tau_{0}}{1+\tau_{0}} \cdot \Delta \tau_{0}+\bar{\varepsilon}_{0}(1) \cdot \frac{\tau_{0}+\Delta \tau_{0}}{1+\tau_{0}+\Delta \tau_{0}} \cdot \Delta \tau_{0}\right\} .
$$

This allows us to state the following:

Proposition 4 (Sufficient Statistics for Large Reforms: Trapezoid). Assume quasi-linear utility and a single tax rate $\tau_{0}$ on taxed goods. In this case, the trapezoid approximation of the efficiency effect of large reforms can be written as

$$
\begin{aligned}
\left.\frac{\Delta W}{\mu_{0}}\right|_{g^{i}=1} \approx & \bar{\varepsilon}_{0} \cdot \frac{\tau_{0}}{1+\tau_{0}} \cdot \Delta \tau_{0} \\
& +\frac{1}{2}\left\{\bar{\varepsilon}_{0} \cdot \Delta\left[\frac{\tau_{0}}{1+\tau_{0}}\right]+\Delta \bar{\varepsilon}_{0} \cdot \frac{\tau_{0}}{1+\tau_{0}}+\Delta \bar{\varepsilon}_{0} \cdot \Delta\left[\frac{\tau_{0}}{1+\tau_{0}}\right]\right\} \cdot \Delta \tau_{0},
\end{aligned}
$$

where $\bar{\varepsilon}_{0}=\bar{\varepsilon}_{0}(0)$ is the elasticity at the initial policy and $\Delta \bar{\varepsilon}_{0}=\bar{\varepsilon}_{0}(1)-\bar{\varepsilon}_{0}(0)$ is the elasticity change 
due to the policy. The first term on the right-hand side is the standard small-reform formula (19), while the second term is the large-reform adjustment. Conditional on the observable tax parameters, the sufficient statistics for welfare are the elasticity level $\bar{\varepsilon}_{0}$ and the elasticity change $\Delta \bar{\varepsilon}_{0}$.

The welfare effect can be written as the standard first-order effect plus an adjustment term. The adjustment term reflects the two errors made by the first-order approach: the error coming from the change in the tax wedge over the reform path and the error coming from the potential change in the elasticity. The correction for these errors has three elements: the change in the tax wedge interacted with the initial elasticity, the change in the elasticity interacted with the initial tax wedge, and the change in the elasticity interacted with the change in the wedge. It seems reasonable to assume that, for most reforms, the last element (the two changes interacted) is small. ${ }^{24}$

Proposition 4 shows that two parameters provide sufficient statistics for evaluating large reforms: the elasticity level $\bar{\varepsilon}_{0}$ and the elasticity change $\Delta \bar{\varepsilon}_{0}$. All other parameters in the formula are directly observable. While the result is conceptually simple, the empirical challenge is that estimating elasticity changes due to policy reforms is not an easy task. Given the difficulties of reaching a consensus on elasticity levels in many settings, how can we hope to reach a consensus elasticity changes? Given the current state of empirical knowledge, we have to impose more structure on the problem in order to assess the welfare impact of large reforms. This implies making a parametric assumption that restricts $\Delta \bar{\varepsilon}_{0}$.

In fully parametric approaches that starts from a specific functional form for utility, there is a set of primitives that determine both $\bar{\varepsilon}_{0}$ and $\Delta \bar{\varepsilon}_{0}$. The simplest approach is to assume iso-elastic utility, in which case we have $\Delta \bar{\varepsilon}_{0}=0$. Under this assumption, we obtain

Proposition 5 (Sufficient Statistics for Large Reforms: Iso-Elastic). Assume quasi-linear, iso-elastic utility and a single tax rate $\tau_{0}$ on taxed goods. In this case, the trapezoid approximation of the efficiency effect of large reforms can be written as

$$
\left.\frac{\Delta W}{\mu}\right|_{g^{i}=1} \approx \bar{\varepsilon}_{0} \cdot\left\{\frac{\tau_{0}}{1+\tau_{0}}+\frac{1}{2} \Delta\left[\frac{\tau_{0}}{1+\tau_{0}}\right]\right\} \cdot \Delta \tau_{0},
$$

a standard Harberger-style formula using a modified tax wedge, $\frac{\tau_{0}}{1+\tau_{0}}+\frac{1}{2} \Delta\left[\frac{\tau_{0}}{1+\tau_{0}}\right]$.

\footnotetext{
${ }^{24}$ Proposition 4 clarifies the conditions under which the standard first-order approach to evaluating large reforms is precise. Equation (30) shows that, all else being equal, the first-order approach will be relatively precise when the initial elasticity $\bar{\varepsilon}_{0}$ is small and when the initial wedge $\frac{\tau_{0}}{1+\tau_{0}}$ is small. In environments with small elasticities and small wedges, we may be comfortable using the first-order approach to assess even very large reforms. Conversely, in settings where initial wedges are large and agents tend to be very elastic, the first-order approach may be very imprecise.
} 
This characterization retains the simple Harberger-style structure, but using an adjusted wedge that accounts for the discreteness of the reform. How big are the quantitative implications of this generalization? As an example, consider a commodity tax of $10 \%$ that is increased to $30 \%$. In this case, the initial wedge equals $\frac{\tau_{0}}{1+\tau_{0}}=0.09$ while the adjusted wedge equals $\frac{\tau_{0}}{1+\tau_{0}}+\frac{1}{2} \Delta\left[\frac{\tau_{0}}{1+\tau_{0}}\right]=$ 0.16 . The adjusted wedge is almost $80 \%$ larger, and so the estimated welfare cost will be almost $80 \%$ larger too. As another example, consider a labor income tax of 50\% that is reduced to $30 \%$. When considering the taxation of supplies, a positive tax rate corresponds to a negative value of $\tau_{0}$. Denoting the labor income tax by $\tau_{l}$, we have $\tau_{0}=-\tau_{l}$. In this case, the initial wedge is given by $\frac{\tau_{l}}{1-\tau_{l}}=1$, while the adjusted wedge is given by $\frac{\tau_{l}}{1-\tau_{l}}+\frac{1}{2} \Delta\left[\frac{\tau_{l}}{1-\tau_{l}}\right]=0.71$. The adjusted wedge is about $30 \%$ smaller, and so the estimated welfare gain will be $30 \%$ smaller. To conclude, the standard first-order approach understates the welfare costs of tax increases and overstates the welfare gain of tax reductions. As demonstrated by the numerical examples, the errors can be quite large for large reforms. ${ }^{25}$

As an alternative to these trapezoid approximations, we may consider higher-order Taylor approximations. Specifically, we now develop a second-order Taylor approximation, showing that this gives similar results as the trapezoid approximation. Around the initial policy $\theta_{0}=0$, the second-order Taylor approximation of social welfare is given by

$$
W(\theta) \approx W(0)+\frac{d W(0)}{d \theta} \theta+\frac{1}{2} \frac{d^{2} W(0)}{d \theta^{2}} \theta^{2} .
$$

Focusing on efficiency $\left(g^{i}=1 \forall i\right)$, the welfare effect of reform, $\Delta W=W(1)-W(0)$, is approximately equal to

$$
\left.\left.\frac{\Delta W}{\mu_{0}}\right|_{g^{i=1}} \approx \frac{d W(0) / d \theta}{\mu_{0}}\right|_{g^{i}=1}+\left.\frac{1}{2} \frac{d^{2} W(0) / d \theta^{2}}{\mu_{0}}\right|_{g^{i}=1} .
$$

To compare the Taylor and trapezoid approaches, let us again consider the special case underlying the standard sufficient statistics formula (19). In this case, we have

$$
\left.\frac{d W(0) / d \theta}{\mu_{0}}\right|_{g^{i=1}}=\bar{\varepsilon}_{0} \cdot \frac{\tau_{0}}{1+\tau_{0}} \cdot \Delta \tau_{0},
$$

\footnotetext{
${ }^{25}$ The numerical examples provided here are not unrealistic. For example, the labor income tax cut corresponds roughly to the tax changes for high-income earners in the Tax Reform Act of 1986 in the U.S. When analyzing such reforms, if we want precise welfare calculations, we have to modify the sufficient statistic formula to account for the changing wedge along the reform path.
} 
and

$$
\left.\frac{d^{2} W(0) / d \theta^{2}}{\mu_{0}}\right|_{g^{i}=1}=\frac{d \bar{\varepsilon}_{0}}{d \theta} \cdot \frac{\tau_{0}}{1+\tau_{0}} \cdot \Delta \tau_{0}+\bar{\varepsilon}_{0} \cdot \frac{\Delta \tau_{0}}{\left(1+\tau_{0}\right)^{2}} \cdot \Delta \tau_{0} .
$$

Therefore, we have

Proposition 6 (Sufficient Statistics for Large Reforms: 2nd-Order Taylor). Assume quasi-linear utility and a single tax rate $\tau_{0}$ on taxed goods. In this case, the second-order Taylor approximation of the efficiency effect of large reforms can be written as

$$
\left.\frac{\Delta W}{\mu_{0}}\right|_{g^{i}=1} \approx \bar{\varepsilon}_{0} \cdot \frac{\tau_{0}}{1+\tau_{0}} \cdot \Delta \tau_{0}+\frac{1}{2}\left\{\bar{\varepsilon}_{0} \cdot \frac{\Delta \tau_{0}}{\left(1+\tau_{0}\right)^{2}}+\Delta \bar{\varepsilon}_{0} \cdot \frac{\tau_{0}}{1+\tau_{0}}\right\} \cdot \Delta \tau_{0},
$$

where $\Delta \bar{\varepsilon}_{0} \approx \frac{d \bar{\varepsilon}_{0}}{d \theta}$ is the elasticity change due to the reform.

As in Proposition 4, the welfare effect can be written as the standard first-order effect plus an adjustment term capturing the discreteness of the reform. The adjustment term under the secondorder Taylor approximation is slightly different than under the trapezoid approximation, because the Taylor expansion starts from the initial policy $\theta_{0}=0$ instead of combining the initial and the new policies. Rather than using the exact change in the wedge $\Delta\left[\frac{\tau_{0}}{1+\tau_{0}}\right]$, equation (36) uses the approximation $\frac{\Delta \tau_{0}}{\left(1+\tau_{0}\right)^{2}}$. Moreover, the Taylor approximation does not include the changes in the elasticity and wedge interacted. These differences may make the Taylor expansion less precise.

We have considered welfare formulas for large reforms using trapezoid and second-order Taylor approximations. The two approaches yield roughly similar results. This is natural given that the Taylor approximation assumes that welfare is a second-order polynomium, while the trapezoid approximation assumes the derivative of welfare is linear. It would be possible to increase the precision of these approximations by considering higher-order Taylor expansions or by applying the trapezoid rule to a finer partitioning of the integration interval. However, this would be empirically pointless as the required moments would be too difficult to estimate. If we are concerned by higher-order effects, it is more natural to go fully structural.

In fact, the relatively simple approaches developed here may already be beyond our empirical reach. There are different views one could take on the approaches developed in this section. One view is that, when considering large reforms (which we almost always do), the analysis has clarified the sufficient statistics that need to be estimated. The elasticity is not enough, we need reform-induced elasticity changes as well. Another view is that elasticity changes are impossible to estimate persuasively, so we have to assume that compensated elasticities are constant over 
large ranges. In this case, we have seen that the sufficient statistics approach corresponds to the case of iso-elastic and quasi-linear utility, which is a particular parametric form. In this sense, the sufficient statistics approach is a structural approach.

\section{Welfare Effect with Non-Government Distortions}

The sufficient statistics literature assumes that government policy is the only source of economic inefficiency. That is, the imposition of taxes or transfers is the only reason for a wedge between private and social incentives, and therefore the welfare effect can be summarized by the fiscal externality. The assumption that the fiscal externality is the only externality is often unrealistic and we will now relax this. It is possible to provide elegant sufficient statistics results in the presence of non-government externalities or internalities, but the estimation requirements increase considerably. ${ }^{26}$

We specify utility as follows

$$
u^{i}\left(x_{0}^{i}, \ldots, x_{J}^{i} ; E_{0}^{i}, \ldots, E_{J}^{i}\right)
$$

where $E_{j}^{i}$ is the externality on individual $i$ due to the consumption of good $j$, which we write as

$$
E_{j}^{i}=\int_{\hat{\imath}} \phi_{j}^{i \hat{\imath}} x_{j}^{\hat{\imath}} d \hat{\imath}
$$

The formulation in (37)-(38) is very general. The weight parameter $\phi_{j}^{i \hat{\imath}}$ captures the externality that individual $\hat{\imath}$ imposes on individual $i$ when consuming good $j$. A few special cases are worth highlighting. First, if $\phi_{j}^{i \hat{\imath}}=1$ for all $i, \hat{\imath}$, then we have an atmospheric externality. These are externalities that depend simply on the aggregate consumption of good $j$; they do not depend on who is generating the externality or who is experiencing it. Examples include the effect of consumption on air pollution, or the effect of consumption on a social norm defined by average consumption in the population. Second, if $\phi_{j}^{i \hat{\imath}}=0$ for $i \neq \hat{\imath}$ and $\phi_{j}^{i \hat{\imath}}=1$ for $i=\hat{\imath}$, then we have $E_{j}^{i}=x_{j}^{i}$. In this case, the externality on individual $i$ is created solely by her own consumption. In other words, there is an internality or a gap between decision utility (which takes $E_{j}^{i}$ for given) and

\footnotetext{
${ }^{26} \mathrm{~A}$ number of recent studies extend the sufficient statistics approach to allow for different forms of externalities and internalities (e.g. Allcott, Mullainathan, and Taubinsky 2014; Piketty, Saez, and Stantcheva 2014; Allcott and Taubinsky 2015; Allcott, Lockwood, and Taubinsky 2019; Farhi and Gabaix 2020). Here we take a general approach that nests most of the settings considered in the literature and clarifies the implications of non-government distortions for the empirical implementation of sufficient statistics approaches.
} 
experienced utility (which is affected by $E_{j}^{i}$ ). Third, if $\phi_{j}^{i i}=1$ and $\phi_{j}^{i \hat{\imath}}=-1$ for $i \neq \hat{\imath}$, then the externality depends on the consumption of individual $i$ relative to the consumption of everybody else as in the case of social status or rat race externalities. Our general formulation captures these and many other cases. ${ }^{27}$

Individuals maximize (37) subject to (3) with respect to $x_{0}^{i}, \ldots, x_{J}^{i}$ taking the external effects $E_{0}^{i}, \ldots, E_{J}^{i}$ as given. This problem is identical to the one considered in the baseline model and the properties are therefore the same. Uncompensated demand/supply functions can be written as $x_{j}^{i}=x_{j}^{i}\left(1+\tau_{0}^{i}, \ldots, 1+\tau_{J}^{i}, Y^{i} ; E_{0}^{i}, \ldots, E_{J}^{i}\right)$ and indirect utility equals $v^{i}\left(1+\tau_{0}^{i}, \ldots, 1+\tau_{J}^{i}, Y^{i} ; E_{0}^{i}, \ldots, E_{J}^{i}\right)$. Using envelope conditions, we have $\partial v^{i} / \partial Y^{i}=\lambda^{i}$ and $\partial v^{i} / \partial\left(1+\tau_{k}^{i}\right)=-\lambda^{i} x_{k}^{i}$.

As before, we specify policy variables as functions of the treatment parameter $\theta$. Because the externalities are not fixed from the perspective of the policy maker, we have $E_{j}^{i}=E_{j}^{i}(\theta)$ when assessing the welfare effect of policy reform. The money-metric effect on utility of any small reform is given by

$$
\frac{d v^{i} / d \theta}{\lambda^{i}}=-\frac{\partial T^{i}}{\partial \theta}+\sum_{j=0}^{J} \frac{\partial v^{i} / \partial E_{j}^{i}}{\lambda^{i}} \frac{d E_{j}^{i}}{d \theta}
$$

The first term is the mechanical revenue effect (as in equation 11), while the second term is the money-metric externality effect.

Social welfare $W(\theta)$ is given by equation (12) and the welfare effect of reform can be expressed as in equation (13). Inserting (39) into (13), we obtain

Proposition 7 (Fiscal Externality and Non-Policy Externalities). In the presence of non-policy externalities specified as in equations (37)-(38), the effect of any small tax reform on economic efficiency equals

$$
\left.\frac{d W / d \theta}{\mu}\right|_{g^{i}=1}=\int_{i}\left[\frac{d T^{i}}{d \theta}-\frac{\partial T^{i}}{\partial \theta}+\sum_{j=0}^{J} \frac{\partial v^{i} / \partial E_{j}^{i}}{\lambda^{i}} \frac{d E_{j}^{i}}{d \theta}\right] d i
$$

where the first term is the fiscal externality (as in Proposition 1) and the second term is the non-policy externality.

The efficiency effect of any small reform equals the sum of the fiscal externality and any nonpolicy externality. The additivity between tax distortions and non-tax externalities echoes early insights from optimal tax theory (see Sandmo 1975 for the case of atmospheric externalities), but here we allow for a more general formulation of externalities. The additivity property implies

\footnotetext{
${ }^{27}$ For example, the framework also encompasses the type of wage bargaining externalities modelled by Piketty, Saez, and Stantcheva (2014).
} 
that the fiscal externality is always an efficiency loss, all else being equal, independently of any other positive or negative externalities that may be present.

The additivity result in equation (40) is general and important, but ultimately not directly operational for policy assessment. In order to provide formulas that are more informative for policy reform design, we have to make stronger assumptions. We make two assumptions. First, we assume that the demands and supplies are independent of the external effects, i.e. $x_{j}^{i}=$ $x_{j}^{i}\left(1+\tau_{0}^{i}, \ldots, 1+\tau_{J}^{i}, Y^{i}\right)$. This corresponds to a separability assumption in utility (37). As an example, while we account for the fact that car transportation creates externalities through air pollution, we assume that the overall level of air pollution does not affect the individual incentive to drive. This is not a weak assumption, but it greatly simplifies the theoretical results and reduces the estimation requirements. If demand is allowed to depend on the externalities (which are themselves functions of demand), then policy reform generally affects the demand for good $j$ by individual $i$ through the tax and virtual income changes of every individual in the population. It would be very hard to estimate the required sufficient statistics in this case.

Second, we put restrictions on the structure of externalities. In particular, we assume that $\phi_{j}^{i \hat{\imath}}=\phi_{I_{j}}^{i} \cdot \mathbf{1}(\hat{\imath}=i)+\phi_{E_{j}}^{i}$, where $\phi_{I_{j}}^{i}$ is an internality (an effect of individual $i$ on herself) and $\phi_{E_{j}}^{i}$ is an externality (an effect of everybody on individual $i$ ). This structure is quite flexible. Different combinations of $\phi_{I_{j}}^{i}$ and $\phi_{E_{j}}^{i}$ encompass all of the examples provided earlier (atmospheric externalities, relative consumption externalities, and internalities).

With these two assumptions, we are able to rewrite equation (40) to a form that is more useful for policy design. Using the tax function $T\left(x_{0}^{i}, \ldots, x_{J}^{i}, \theta\right)$ and the externality function (38), we have

$$
\left.\frac{d W / d \theta}{\mu}\right|_{g^{i}=1}=\int_{i} \sum_{j=0}^{J}\left[\tau_{j}^{i} \frac{d x_{j}^{i}}{d \theta}+\frac{\partial v^{i} / \partial E_{j}^{i}}{\lambda^{i}} \int_{\hat{\imath}} \phi_{j}^{i \hat{\imath}} \frac{d x_{j}^{\hat{\imath}}}{d \theta} d \hat{\imath}\right] d i .
$$

Using $\phi_{j}^{i \hat{\imath}}=\phi_{I_{j}}^{i} \cdot \mathbf{1}(\hat{\imath}=i)+\phi_{E_{j}}^{i}$, this can be rewritten as

$$
\left.\frac{d W / d \theta}{\mu}\right|_{g^{i}=1}=\int_{i} \sum_{j=0}^{J}\left[\left(\tau_{j}^{i}+\tau_{I_{j}}^{i}+\tau_{E_{j}}\right) \frac{d x_{j}^{i}}{d \theta}\right] d i
$$

Here $\tau_{I_{j}}^{i} \equiv \frac{\partial v^{i} / \partial E_{j}^{i}}{\lambda^{i}} \cdot \phi_{I_{j}}^{i}$ is a "tax wedge" that captures the internality from good $j$ on individual $i$ (the uninternalized, money-metric utility effect of consuming an extra unit of good $j$ by individual $i$ ), while $\tau_{E_{j}} \equiv \int_{i} \frac{\partial v^{i} / \partial E_{j}^{i}}{\lambda^{i}} \cdot \phi_{E_{j}}^{i} d i$ is a "tax wedge" that captures the externality from good $j$ (the average uninternalized, money-metric utility effect of consuming an extra unit of good $j$ 
across all individuals). From before we have

$$
\frac{d x_{j}^{i}}{d \theta}=\sum_{k=0}^{J} x_{j}^{i} \varepsilon_{j k}^{i} \frac{d \tau_{k}^{i} / d \theta}{1+\tau_{k}^{i}}-x_{j}^{i} \eta_{j}^{i} \frac{\partial T^{i} / \partial \theta}{Y^{i}}
$$

which allows us to state the following:

Proposition 8 (Sufficient Statistics with Non-Policy Externalities). In the presence of non-policy externalities specified as in equations (37)-(38), the effect of any small tax reform on economic efficiency can be written as

$$
\left.\frac{d W / d \theta}{\mu}\right|_{g^{i}=1}=\int_{i}\left[\sum_{j=0}^{J} \sum_{k=0}^{J} \hat{\tau}_{j}^{i} x_{j}^{i} \varepsilon_{j k}^{i} \frac{d \tau_{k}^{i} / d \theta}{1+\tau_{k}^{i}}-\sum_{j=0}^{J} \hat{\tau}_{j}^{i} x_{j}^{i} \eta_{j}^{i} \frac{\partial T^{i} / \partial \theta}{Y^{i}}\right] d i
$$

where $\hat{\tau}_{j}^{i} \equiv \tau_{j}^{i}+\tau_{I_{j}}^{i}+\tau_{E_{j}}$ is the total wedge on good $j$ for individual $i$. Therefore, conditional on a set of observables (tax parameters, expenditure and earnings levels), the sufficient statistics for evaluating reform are $\left\{\hat{\tau}_{j}^{i}, \varepsilon_{j k}^{i}, \eta_{j}^{i}\right\}_{\forall j, k, i}$.

This generalizes our previous expression (18) to allow for a wide range of non-government distortions. The set of estimable sufficient statistics includes both elasticities and externalityadjusted wedges.

As before, we can simplify the welfare formula to a Harberger-style formula that depend on just one elasticity, but the assumptions required are stronger now. This is because assumptions on the structure of the "tax system" amounts to assumptions on the structure of both tax and non-tax distortions in this more general model. For example, if we assume that (i) utility is quasilinear $\left(\eta_{j}^{i}=0 \forall j, i\right)$, (ii) only good 0 is distorted $\left(\hat{\tau}_{j}^{i}=0\right.$ for $j \geq 1$ ), and (iii) both the tax and non-tax distortions of good 0 are homogeneous across individuals $\left(\tau_{0}^{i}=\tau_{0}\right.$ and $\left.\hat{\tau}_{0}^{i}=\hat{\tau}_{0}\right)$, then the efficiency effect of changing $\tau_{0}$ is given by

$$
\left.\frac{d W / d \theta}{\mu}\right|_{g^{i}=1}=\bar{\varepsilon}_{0} \cdot \frac{\hat{\tau}_{0}}{1+\tau_{0}} \cdot \frac{d \tau_{0}}{d \theta}
$$

where $\bar{\varepsilon}_{0} \equiv \int_{i} x_{0}^{i} \varepsilon_{00}^{i} d i$. Hence, the only thing that has changed compared to the standard sufficient statistic formula (19) is that the wedge $\frac{\tau_{0}}{1+\tau_{0}}$ has been replaced by the adjusted wedge $\frac{\hat{\tau}_{0}}{1+\tau_{0}}$. The latter has to be estimated and so, given the directly observable tax parameters, the sufficient statistics are $\bar{\varepsilon}_{0}$ and $\hat{\tau}_{0}$. 


\section{Conclusion}

This paper has revisited the foundations of the sufficient statistics approach, clarified its advantages and limitations, and provided a number of generalizations. The approach builds on an envelope theorem logic according to which the efficiency effect of any small policy reform can be expressed as a fiscal externality from behavioral responses to the reform. This fiscal externality is equal to the interaction - or a set of interactions - between reduced-form elasticities and taxtransfer wedges. Therefore, the welfare analysis of small reforms is possible without estimating the structural primitives of fully specified models, but based on non-parametrically identified elasticities. Given the assumptions, the logic is simple and powerful.

In this paper, we highlight three challenges in the practical implementation of the sufficient statistics approach. First, without putting any restrictions on the environment or preferences, the resulting sufficient statistics formulas are difficult to implement empirically. It is theoretically feasible to develop general results that allow for dynamics and general equilibrium effects, but estimating the required dynamic own-price and cross-price elasticities without making any parametric assumptions is beyond our reach. In fact, many papers in the sufficient statistic tradition start from a set of high-level structural assumptions (quasi-linear preferences, separability assumptions, static environments, etc.) and derive "sufficient statistics" conditional on those assumptions. Here we start from a general formulation, making it transparent how different combinations of assumptions lead to simple sufficient statistics formulas based on just one or two elasticities.

Second, existing sufficient statistics approaches are exact only for infinitessimal reforms, but the reforms being studied are never infinitessimal. ${ }^{28}$ We develop a sufficient statistics approach for large reforms that serves two purposes: (i) it elucidates the nature and magnitude of the measurement error when assessing discrete reforms using the first-order approach, (ii) it characterizes a set of sufficient statistics for the precise welfare analysis of discrete reforms. We show that the welfare effect of large reforms can be (approximately) expressed in terms of the same reduced-form elasticities as the standard formula along with the change in those reduced-form elasticities due to the reform. It may well be that those elasticity changes cannot be estimated non-parametrically, in which case our analysis shows that the sufficient statistics approach is in

\footnotetext{
${ }^{28}$ In the optimal tax literature we do study infinitessimal reforms, because they can be used to characterize the optimal policy rules (see e.g., Saez 2001; Piketty and Saez 2013). However, as explained above, these are hypothetical pertubations around a social optimum and the implementation of the resulting policy rules requires global knowledge and demand and supply functions. Therefore, optimal policy implementation requires a fully structural approach.
} 
fact a structural approach based on iso-elastic preferences.

Finally, most sufficient statistics approaches assume away any non-government distortions. Allowing for a general formulation of non-government externalities and internalities, we present sufficient statistics results that retain the standard form: welfare can be expressed as a set of interactions between behavioral elasticities and modified "tax wedges" that include the uninternalized money-metric utility effect of all externalities and internalities. This reflects the simple insight that, in the presence of non-government market imperfections, the welfare effect equals the total externality (fiscal and non-fiscal) from behavioral responses to the policy. The empirical challenge is that we have to estimate both the behavioral elasticities and the externality-inclusive wedges; they enter the welfare formula symmetrically and are therefore equally important. For example, if we are considering taxes on high-income earners, we need to estimate both their behavioral elasticity and the potential gap between their private and social marginal products of effort. In the sufficient statistics spirit, our results highlight that welfare evaluation in the presence of non-policy distortions does not require a fully specified model of the different market imperfections. It is sufficient to estimate "reduced-form" gaps between private and social prices in conjunction with the behavioral elasticities that we normally estimate.

To conclude, the sufficient statistics approach has important strengths and will remain influential: it relies on a widely applicable logic, it provides clear economic intuition, and it establishes a transparent link between theory and data. This separates the approach from traditional structural approaches to welfare analysis, which can be opaque and difficult to evaluate. At the same time, this review has elucidated the limitations of a loftier goal often purported in the sufficient statistics literature (see e.g., Chetty 2009b; Chetty and Finkelstein 2013): the idea that welfare and optimal policy formulas expressed in terms of a few reduced-form elasticities are robust across a broad class of underlying models, thus avoiding strong structural assumptions. In practice, sufficient statistics implementations rely on implicit and strong assumptions on the decision environment (such as assumptions about dynamics, uncertainty, and policy instruments) and preferences (such as assumptions about separability, quasi-linearity, and constancy of elasticities). The simplicity and transparency of the sufficient statistics approach is important, but in feasible empirical implementations it is a structural approach. 


\section{References}

Allcott, Hunt, Benjamin B. LockWood, and Dmitry TAubinsky (2019): “Regressive Sin Taxes, with an Application to the Optimal Soda Tax," The Quarterly Journal of Economics, 134(3), 1557-1626. 22

Allcott, Hunt, Sendhil Mullainathan, and Dmitry Taubinsky (2014): “Energy Policy with Externalities and Internalities," Journal of Public Economics, 112, 72-88. 22

Allcott, Hunt, And Dmitry TAubinsky (2015): “Evaluating Behaviorally Motivated Policy: Experimental Evidence from the Lightbulb Market," American Economic Review, 105(8), 25012538. 22

BAiLy, MARTin N. (1978): “Some Aspects of Optimal Unemployment Insurance," Journal of Public Economics, 10(3), 379-402. 8

Browning, Edgar K. (1976): “The Marginal Cost of Public Funds,” Journal of Political Economy, 84(2), 283-298. 8

(1987): “On the Marginal Welfare Cost of Taxation," American Economic Review, 77(1), 11-23. 8

CHetty, RAJ (2006): “A General Formula for the Optimal Level of Social Insurance," Journal of Public Economics, 90(10), 1879-1901. 8

(2008): “Moral Hazard versus Liquidity and Optimal Unemployment Insurance," Journal of Political Economy, 116(2), 173-234. 8

(2009a): "Is the Taxable Income Elasticity Sufficient to Calculate Deadweight Loss? The Implications of Evasion and Avoidance," American Economic Journal: Economic Policy, 1(2), 3152. 8

(2009b): "Sufficient Statistics for Welfare Analysis: A Bridge Between Structural and Reduced-Form Methods," Annual Review of Economics, 1(1), 451-488. 1, 3, 10, 27

Chetty, RAJ, And Amy Finkelstein (2013): “Social Insurance: Connecting Theory to Data," in Handbook of Public Economics, ed. by A. J. Auerbach, R. Chetty, M. S. Feldstein, and E. Saez, vol. 5, pp. 111-193. Elsevier: Amsterdam, NL. 8, 27 
Corlett, Wilfred J., And Douglas C. Hague (1953-1954): “Complementarity and the Excess Burden of Taxation," Review of Economic Studies, 21(1), 21-30. 1, 14

Currie, Janet, Henrik J. Kleven, and Esmée Zwiers (2020): “Technology and Big Data Are Changing Economics: Mining Text to Track Methods," AEA Papers and Proceedings, p. forthcoming. 1,32

DiAmOnd, Peter A. (1998): “Optimal Income Taxation: An Example With a U-Shaped Pattern of Optimal Marginal Tax Rates," American Economic Review, 88(1), 83-95. 8

Diamond, Peter A., And James A. Mirrlees (1971): “Optimal Taxation and Public Production I: Production Efficiency, and II: Tax Rules," American Economic Review, 61(1), 8-27. 8

DONALDSON, DAVE (2018): "Railroads of the Raj: Estimating the Impact of Transportation Infrastructure," American Economic Review, 108(4-5), 899-934. 8

Dupuit, Jules (1844): “De la Mesure de l'Utilité des Travaux Publics," Annales des Ponts et Chaussées, 8, Translated and reprinted in International Economic Papers, 2, 1952, 83-110. 1

Eissa, NADA, Henrik J. Kleven, and Claus Thustrup KReiner (2006): “Welfare Effects of Tax Reform, and Labor Supply at the Intensive and Extensive Margins," in Tax Policy and Labour Market Performance, ed. by J. Agell, and P. B. Sørensen. MIT Press: Cambridge, MA. 6, 7, 8

- (2008): “Evaluation of Four Tax Reforms in the United States: Labor Supply and Welfare Effects for Single Mothers," Journal of Public Economics, 92(3-4), 795-816. 6, 7, 8

Farhi, Emmanuel, And XaVier Gabaix (2020): “Optimal Taxation with Behavioral Agents," American Economic Review, 110(1), 298-336. 22

FELdSTEIN, MARTIN (1995): “The Effect of Marginal Tax Rates on Taxable Income: A Panel Study of the 1986 Tax Reform Act," Journal of Political Economy, 103(3), 551-572. 11

— (1999): “Tax Avoidance and the Deadweight Loss of the Income Tax," Review of Economics and Statistics, 81(4), 674-680. 2, 8, 11

Finkelstein, Amy, And Matthew J. Notowidigdo (2019): “Take-Up and Targeting: Experimental Evidence from SNAP," The Quarterly Journal of Economics, 134(3), 1505-1556. 8 
Goulder, Lawrence H., and Roberton C. Williams (2003): “The Substantial Bias From Ignoring General Equilibrium Effects in Estimating Excess Burden, and a Practical Solution," Journal of Political Economy, 111(4), 898-927. 8

HARberger, ARnOld C. (1964): “The Measurement of Waste," American Economic Review, 54(3), 58-76. 1,8

Hendren, Nathaniel (2016): “The Policy Elasticity," Tax Policy and the Economy, 30(1), 51-89. 6,8

Hines, JAMES R. (1999): “Three Sides of Harberger Triangles," Journal of Economic Perspectives, 13(2), 167-188. 1

Hotelling, Harold (1938): "The General Welfare in Relation to Problems of Taxation and of Railway and Utility Rates," Econometrica, 6(3), 242-69. 1

Jakobsen, Katrine, Kristian Jakobsen, Henrik J. Kleven, and Gabriel Zucman (2020): “Wealth Taxation and Wealth Accumulation: Theory and Evidence from Denmark," The Quarterly Journal of Economics, 135(1), 329-388. 13

Kleven, HenriK J. (2004): “Optimum Taxation and the Allocation of Time," Journal of Public Economics, 88(3-4), 545-557. 16

— (2016): “Bunching," Annual Review of Economics, 8(1), 435-464. 5

(2020): “The EITC and the Extensive Margin: A Reappraisal," NBER Working Paper No. 26405. 9

Kleven, Henrik J., And Claus Thustrup Kreiner (2002): “The Taxation of Married Couples in OECD Countries: A Need for Reform?," EPRU Working Paper No. 2002-13. 6

- (2005): "Labor Supply Behavior and the Design of Tax and Transfer Policy," Danish Journal of Economics, 143(2005), 321-358. 2, 7, 8

(2006): “The Marginal Cost of Public Funds: Hours of Work Versus Labor Force Participation," Journal of Public Economics, 90(10-11), 1955-1973. 6, 7, 8

Kolsrud, Jonas, Camille Landais, Peter Nilsson, and Johannes Spinnewijn (2018):

“The Optimal Timing of Unemployment Benefits: Theory and Evidence from Sweden," American Economic Review, 108(4-5), 985-1033. 8 
Michaillat, Pascal, and Emmanuel Saez (2019): “Optimal Public Expenditure with Inefficient Unemployment," Review of Economic Studies, 86(3), 1301-1331. 8

Piketty, Thomas, and Emmanuel Saez (2013): “Optimal Labor Income Taxation,” in Handbook of Public Economics, ed. by A. J. Auerbach, R. Chetty, M. S. Feldstein, and E. Saez, vol. 5, pp. 391-474. Elsevier: Amsterdam, NL. 15, 26

Piketty, Thomas, Emmanuel Saez, and Stefanie Stantcheva (2014): “Optimal Taxation of Top Labor Incomes: A Tale of Three Elasticities," American Economic Journal: Economic Policy, 6(1), 230-271. 3, 12, 22, 23

RAMSEY, FRANK P. (1927): “A Contribution to the Theory of Taxation," Economic Journal, 37(145), 47-61. 1

Saez, Emmanuel (2001): “Using Elasticities to Derive Optimal Income Tax Rates," Review of Economic Studies, 68(1), 205-229. 8, 15, 26

(2004): “Reported Incomes and Marginal Tax Rates, 1960-2000: Evidence and Policy Implications," Tax Policy and the Economy, 18, 117-173. 2, 12

_ (2010): “Do Taxpayers Bunch at Kink Points?," American Economic Journal: Economic Policy, 2(3), 180-212. 5

Saez, Emmanuel, Joel Slemrod, and Seth H. Giertz (2012): “The Elasticity of Taxable Income with Respect to Marginal Tax Rates: A Critical Review," Journal of Economic Literature, 50(1), 3-50. 12

SANDMO, AGNAR (1975): "Optimal Taxation in the Presence of Externalities," Swedish Journal of Economics, 77(1), 86-98. 23

Slemrod, Joel, AND SHLOMO YitzhaKi (1996): “The Costs of Taxation and the Marginal Efficiency Cost of Funds," Staff Papers, 43(1), 172-198. 8

- (2001): “Integrating Expenditure and Tax Decisions: The Marginal Cost of Funds and the Marginal Benefit of Projects," National Tax Journal, 54(2), 189-201. 8 


\section{Figure 1: Fraction of Academic Articles Referring to the Sufficient StATISTICS APPROACH}

\section{A: Public Economics}

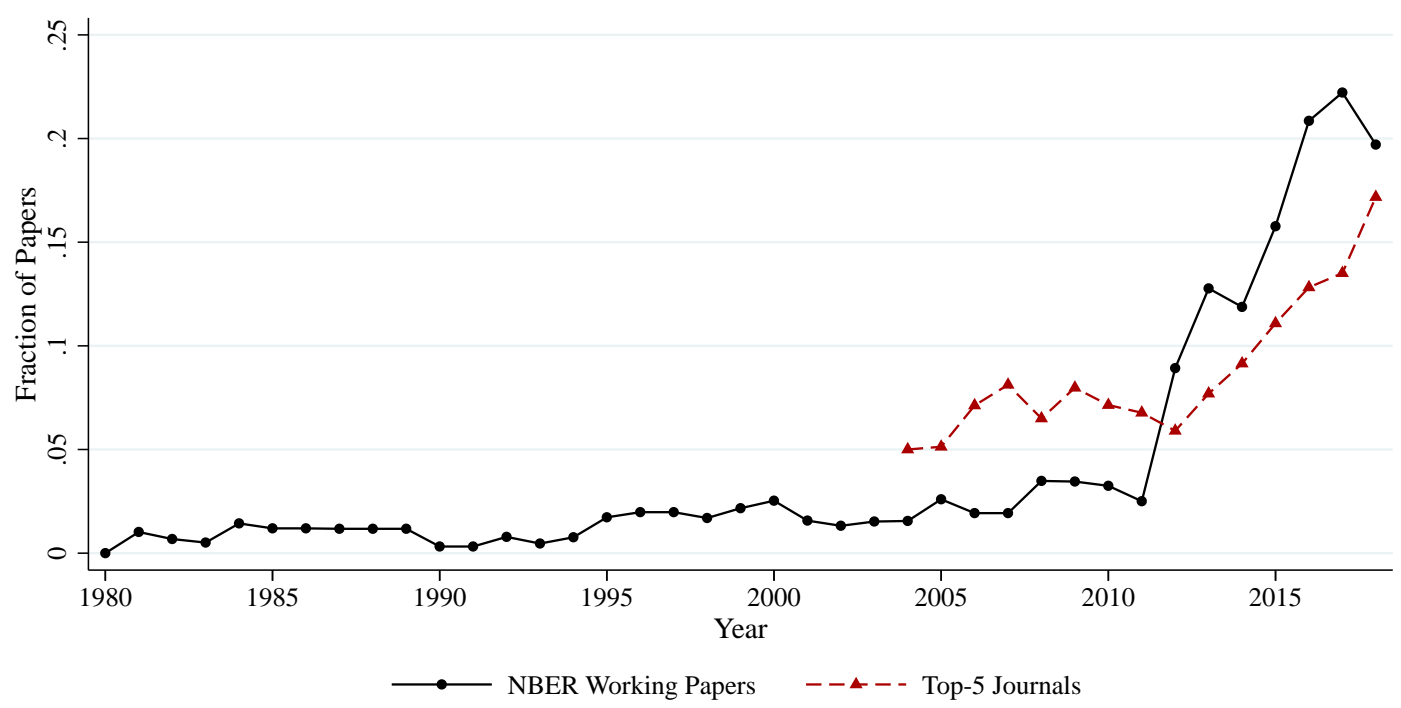

\section{B: All Economics}

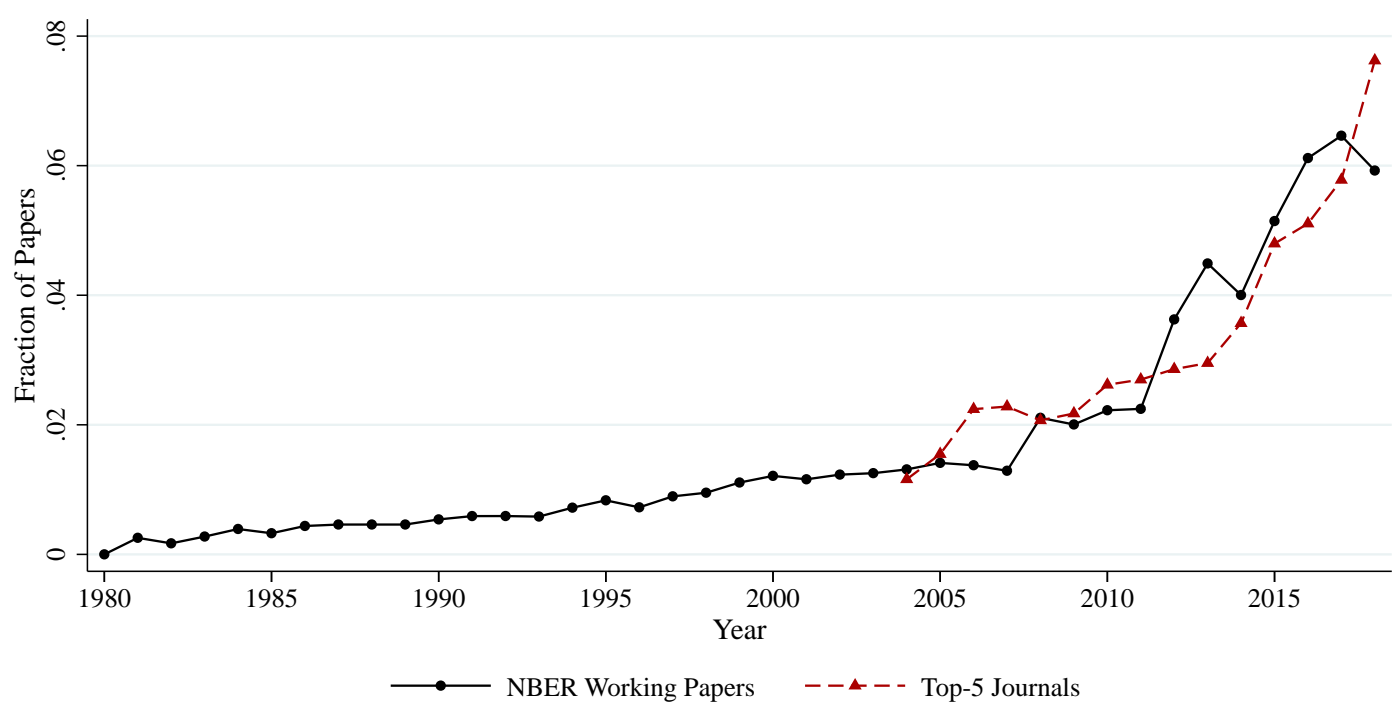

Notes: This figure shows the fraction of papers in the NBER working paper series (from 1980 to 2018) and in topfive economics journals (from 2004 to 2018) that refer to the sufficient statistics approach. The top-five journals are American Economic Review, Econometrica, Journal of Political Economy, Quarterly Journal of Economics, and Review of Economic Studies. Panel A restricts attention to papers from the field of Public Economics, while Panel B includes papers from all fields of economics. The fractions are 5-year moving averages. To be counted as a sufficient statistic paper, the text must contain at least one sentence (between two full stops) with at least one word from each of the following three sets of words: (1) "parameter(s)", "elasticity(ies)", "response(s)", "responsiveness", "statistic(s)"; (2) "(in)sufficient(ly)", "(in)sufficiency"; (3) "(in)efficient(ly)", "(in)efficiency", "welfare", "deadweight", "excess burden", "optimal(ly)(ity)". See Currie, Kleven, and Zwiers (2020) for additional details on data and methods. 